Synthesis, vol. 24 n 2 , e026, diciembre2017. ISSN 1851-779X

Universidad Nacional de La Plata.

Facultad de Humanidades y Ciencias de la Educación.

Centro de Estudios Helénicos

\title{
Laura Swift, Greek Tragedy: Themes and Contexts. Classical World, Bloomsbury Academic, London, 2016, 144 pp.
}

Cita sugerida: Fernández Deagustini, M. del P.(2017). [Revisión del libro Greek Tragedy: Themes and Contexts. Classical World, por Laura Swift]. Synthesis, 24 (2), e026. https://doi.org/10.24215/1851779Xe026 


\section{Laura Swift, Greek Tragedy: Themes and Contexts. Classical World, Bloomsbury}

Academic, London, 2016, 144 pp.

Maria del Pilar Fernández Deagustini

Universidad Nacional de La Plata / CONICET,

Argentina

Laura Swift es Senior Lecturer in Classics de la Universidad Abierta del Reino Unido (The Open University, OU). Su campo de investigación es vasto, ya que estudia la lírica arcaica y el drama clásico griegos. En 2008 ha publicado Euripides: Ion (London, Bloomsbury Academic) y, en 2010, The Hidden Chorus. Echoes of Genre in Tragic Lyric (Oxford, OUP), en el que ha investigado las relaciones entre el coro trágico y otros tipos de canciones corales, fundamentales para comprender la cultura y sociedad griegas en la antigüedad. Greek Tragedy: Themes and Contexts es su última publicación. Reseñar este nuevo libro implica referirse a su autora, por su firme compromiso de llevar las letras clásicas a un público más amplio y por su participación en numerosas actividades que, fuera del ambiente universitario, procuran alcanzar este objetivo.

El último volumen en la serie Classical World es un material destacable, porque logra materializar el proyecto de la autora. El libro ofrece una indispensable y actualizada introducción al género trágico, de lectura ligera, deliberadamente diferenciada de los modelos de los manuales y las Historias de la Literatura que tradicionalmente han guiado nuestras clases. Tal como lo explicita la autora en el prefacio, logra ser particularmente accesible para el lector general, tanto como para estudiantes escolares y universitarios, ya que no requiere de ningún conocimiento de la lengua griega. Pero, sin duda, resulta un insumo realmente valioso para quienes tenemos la vocación y la tarea de despertar la curiosidad por la tragedia griega clásica en escuelas, institutos terciarios y universidades. Su cualidad más sobresaliente es que la ambiciosa propuesta del título se cumple, con un acertado y excelente enfoque, en las poco más de cien páginas que lo integran.

Resulta oportuno destacar que, a diferencia de otra bibliografía que se propone como introductoria al género, esta publicación no incluye interpretaciones o análisis de obras escogidas entre las conservadas, sino que se concentra en citar pasajes de las tragedias que apoyen la propuesta de un tema dado, según la organización de cada capítulo. Asimismo, resulta una elección interesante de la autora el hecho de que refiera muy sucintamente al contexto histórico, tanto político como religioso. Esto logra que el lector pueda concentrarse en el objetivo primordial del libro, explicar qué distingue a la tragedia griega de otros tipos de poesía, qué lo define como género y cuáles son sus principales preocupaciones, que son las tres metas a las que promete arribar Swift en el prefacio. En estas palabras preliminares, resulta sugestivo otro gesto crítico frente a los abordajes estereotipados del manual, dado que, a pesar de proponerse como un libro introductorio, la autora llama la atención sobre diversos lugares comunes en los que es frecuente caer cuando se enseña sobre tragedia griega clásica. Swift no demora en señalar que las tragedias conservadas muestran una gran diversidad en su composición y que, por lo tanto, no pretende proponer una "fórmula" que simplifique su definición. No obstante, el libro pretende mostrar que pueden encontrarse ciertas continuidades que permiten apreciar mejor el rol de este género en la vida ateniense del siglo $\mathrm{V}$ a. $\mathrm{C}$.

La publicación se organiza en ocho capítulos. Los dos primeros, "Tragedy as a Genre” y "Aeschylus, Sophocles, and Euripides” proponen una visión de conjunto de la tragedia griega clásica. “Qué hace de algo una tragedia?" es la pregunta con la que Swift inaugura el primero de ambos, en el que explora lo que la audiencia antigua habría esperado ver al ir al teatro. Con este propósito, investiga los orígenes del género, el 
contexto performativo y las características de estilo de la tragedia griega, y examina qué es lo que la diferencia de otras formas de poesía. En este último punto, la autora expone y cuestiona la influencia de la Poética de Aristóteles sobre las posteriores miradas sobre el género y, especialmente, sobre las obras conservadas. Asimismo, destaca el valor didáctico que tenía la tragedia en la vida de los atenienses. Su ambicioso propósito se logra en poco más de diez páginas, en las que se limita a destacar que la tragedia floreció acompañando a la democracia.

El segundo capítulo introduce sucintamente la obra de Esquilo, Sófocles y Eurípides. No obstante, lo más destacable es la preocupación por poner en duda los estereotipos asociados a estos tres trágicos. La autora llama la atención sobre la manera en la que los textos antiguos fueron preservados y, como consecuencia, sobre el hecho de que el teatro griego trágico del siglo $\mathrm{V}$ esté dominado por un "pequeño número de grandes nombres", ya considerados clásicos en la comedia aristofánica. Por ello, Swift también pone en evidencia el grado de influencia de la comedia Ranas sobre la recepción de estos poetas, es decir, el conocido patrón de "desarrollo, pináculo y caída" que todavía marca la manera en la que son abordados en las escuelas y universidades. Es tras esta llamada de atención sobre la cautela que debe anteponerse a la lectura deliberadamente humorística de Aristófanes, que Swift introduce un breve apartado a cada uno de los tres trágicos, en los que no deja de señalar sus más sobresalientes y tradicionalmente reconocidas particularidades.

Lo sustantivo de la tragedia, es decir, aquello que aparece específicamente asociado con la antigua definición del género, ocupa los tres capítulos centrales: "Myth", "Heroes", and "The Gods". En "Myth" se explora el rol que el mito juega en la tragedia griega, el impacto de componer obras en un mundo de tramas y personajes conocidos y el grado hasta el cual los poetas pudieron adaptar y variar los mitos. Swift ilumina esta flexibilidad descubriendo la innovación en el mito de la Orestíada y las obras protagonizadas por Electra.

En el cuarto capítulo, "Heroes", Swift discute la Poética. La autora señala que el interés de Aristóteles en el personaje del héroe ha sido el primero de los muchos intentos de definir lo que es típico acerca del héroe trágico. El capítulo explora si es correcto buscar un único modelo para el heroísmo trágico y qué características distintivas pueden encontrarse en las obras conservadas. Finalmente, Swift investiga el rol del culto al héroe, como puente entre la edad heroica y la de la audiencia, y examina cómo el culto es usado para compensar a los héroes trágicos por el sufrimiento padecido. Nuevamente el libro propone un examen de "lo establecido": si bien la mirada aristotélica de Poética $1452 \mathrm{~b}-53 \mathrm{a}$ ha sido de una influencia notable sobre las miradas más modernas, no debemos aceptar la posición aristotélica sin someterla a una actitud crítica. Por ello, el primer apartado de este capítulo discute la visión aristotélica de la tragedia, concentrándose particularmente en el concepto de hamartía. En consonancia con este punto de vista, Swift también pone en cuestión el modelo de análisis de Bernard Knox en su libro The tragic Temper, quien aplica las ideas aristotélicas a las obras de Sófocles para establecer un patrón. El rol del héroe trágico es analizado utilizando como ejemplos a Edipo, Áyax e Hipólito.

En el quinto capítulo, titulado "The Gods”, Swift considera la tensión entre la voluntad humana y la divina. Respecto del contexto en el que se desarrrolló la tragedia, la autora advierte al lector sobre la falta de división entre los mundos divino y secular, explicando cómo los festivales, como las Grandes Dionisias, combinaban lo que desde nuestra actualidad percibimos como actividades y ámbitos separados. El capítulo explora cómo se comportan los dioses trágicos, si es posible hablar de una teología trágica y si es posible encontrar diferencias entre los dramaturgos. Se le dedica un apartado especial a los dioses euripideos, dada su proficua aparición en las tragedias conservadas.

Los tres capítulos restantes, titulados "Contemporary Thought", "Gender and the Family" y "Chorus" muestran diferentes formas en las que el género se compromete con la vida de la comunidad ateniense. En "Contemporary Thought", la autora señala que la tragedia se involucró con la vida intelectual de su comunidad, en una Atenas que, en el siglo $\mathrm{V}$, se convirtió en un imán para los pensadores de todo el mundo griego, en un centro para la especulación acerca de tópicos que atravesaban las ciencias naturales, la metafísica, la ética, la política filosófica y el estudio de la retórica. El capítulo muestra cómo los tres tragediógrafos 
se comprometieron con los tópicos intelectuales. Para ello, la autora se enfoca en tres áreas que considera centrales para el pensamiento del siglo V: el rol de la naturaleza y la cultura (nómos y physis) en la sociedad, cómo los griegos se diferenciaban de los extranjeros y el rol de la retórica en la vida pública.

El séptimo capítulo, "Gender and the Family", es inaugurado por una aseveración clave: que la tragedia representa un mundo donde la estabilidad y la autoridad son desafiadas y quebradas. Swift destaca que, como la familia es la primera unidad de la sociedad (ồkos), la tragedia está atravesada por familias disfuncionales. La autora observa que, como el espacio doméstico fue la fuente de autoridad y estatus de las mujeres en el mundo griego, el interés de los dramaturgos por los roles familiares también implicó un notable interés en las vidas de las mujeres. Específicamente, en el capítulo discute cómo, en la tragedia griega, hombres y mujeres se comportan el uno con el otro, cómo esto refleja cuestiones reales de la sociedad y qué tienen que decir las obras acerca de la vida familiar. La autora advierte sobre el hecho de que las mujeres y el matrimonio son centrales para la tragedia, pero que, como las relaciones de género son recíprocas, las tramas conservadas también informan ampliamente acerca de la masculinidad. Swift comienza contextualizando someramente el estatus de las mujeres en la Atenas clásica, para luego concentrarse en las figuras de las "malas esposas", Clitemnestra y Medea, y las familias disfuncionales de Edipo e Hipólito.

El último capítulo del libro está consagrado a lo que Swift considera como el aspecto más desafiante de la tragedia griega, tanto para los lectores que se aproximan a las obras por primera vez como para los directores que desean ponerlas en escena: el coro. La autora señala tres problemas: por un lado, el del texto conservado como insumo parcial del espectáculo; por el otro, nuestra distancia cultural respecto de este tipo de prácticas en las que la canción es usada para crear lo que ella llama "solidaridad grupal". En tercer lugar, menciona la dificultad de acercarse al coro por su "estilo elusivo". Por eso, el propósito del capítulo es demostrar la centralidad que tenía el coro para la audiencia de la Grecia Clásica, explicando el rol que la performance coral tenía en la sociedad. En la primera parte del capítulo discute el legado de la "coralidad" en la vida griega; en la segunda examina la función del coro en la tragedia y los desafíos a los que debemos enfrentarnos cuando tratamos de interpretar su rol. Finalmente, el capítulo explora en detalle la contribución de ciertas odas corales, la "oda al hombre" de Antígona (332-375) y la "oda a Atenas" de Medea (824-865). En este apartado, la autora deja ver su pericia en el tema.

Excepto en la elección y cuidadoso análisis de las odas trágicas que protagonizan el último capítulo, Swift honra el subtítulo, Themes and Contexts. No cuenta los argumentos de las obras, sino que refiere a ellas con el claro objetivo de ilustrar los temas que selecciona para explicar qué es la tragedia griega. Sus asertos están adecuadamente apoyados por bibliografía crítica de primer nivel y absolutamente actualizada, tanto como por citas textuales traducidas por la propia autora.

La información suplementaria incluye una línea de tiempo ("Chronology") que ordena cronológicamente las tragedias conservadas (excluyendo las controvertidas Reso y Prometeo encadenado) vinculadas con otros eventos trascendentes en la vida de los dramaturgos y la historia de Atenas; un práctico glosario que compendia el vocabulario específico inherente al estudio del género ("Glossary of Greek and Technical Terms Used"); una lista de sugerencias para continuar la lectura, integrada por una sucinta pero muy pertinente bibliografía ("Suggestions for Further Reading") y un útil Index.

¿Qué es la tragedia? ¿Cómo debemos o podemos comprenderla y estudiarla en la actualidad? Greek Tragedy: Themes and Contexts resulta un práctico, breve y agudo libro que incita a profundizar el estudio del género trágico, ofreciendo una concisa pero crítica mirada para los principiantes. 